\title{
TEXTILE FIBERS AS A REINFORCEMENT FOR ASPHALT CONCRETE MIXTURES
}

\author{
By \\ Dr. Saad El-Hamrawy \\ Dr.Abou El Hassan Rahil \\ Faculty of Eng., El-Menoufia Uni.
}

\section{ABSTRACT}

Growing road traffic has created the need of pavement structures which can adapt to this evolution. Concurrently, surfacing techniques have moved in the same direction to ensure user comfort and safety. Also, to resist the high deformation caused by these high loads.

Stone-Mastic-Asphalt-mixtures (SMA) have been developed in Germany since 1984, and another mixtures were developed in France.

In this investigation, a comparative study was made between SMA and mixtures produced using coarse gradation $3 \mathrm{~B}$, according to the specs of RBA. Also, a comparison was made between the two last mixtures and -the most common mixture in Egypt- the dense gradation $4 \mathrm{C}$.

It was concluded that the coarse gradation mixtures must be used with additives to increase the Marshall stability and to improve the tensile strength.

\section{INTRODUCTION}

During recent years, high traffic volumes and heavy traffic loads affecting the road construction. These high loads lead to high deformation and increase the rutting depth of asphalt concrete layers.

Manuscript received from Dr.Abou El Hassan Rahil at: 13/ 4/1998, accepted at: $28 / 5 / 1998$, Engineering research bulletin, Vol. 21, No. 2, 1998, Menoufiya University, Faculty of Engineering, Shebin El- Kom, Egypt, ISSN. 1110-1180. 
In Europe, the different mixtures have been developed; for example, hot rolled asphalt appeared in Great Britain and stone mastic asphalt \{SMA\} came out in Germany. It must be emphasis that more than $10 \%$ of Pavements in Germany are constructed with Stone-Mastic-Asphalt mixes (SMA) [1]. In Egypt, most pavements constructed according to the ASTM specifications using dense gradations (DG) $4 \mathrm{C}$ or $4 \mathrm{D}$.

The main objective of this investigation is to compare between the stone mastic asphalt, ( German specifications) and the mixes with coarse gradation 3 B, (ASTM specifications). Also, a trial was made to improve the structural properties of coarse gradation $3 \mathrm{~B}$ (CG) to meet the characteristic of SMAmixes by adding short textile fibers as additives. Moreover, a comparative study was made between coarse gradation $3 \mathrm{~B}$ and dense gradation $4 \mathrm{C}$.

\section{BACKGROUND:}

Stone Mastic Asphalt (SMA) is a gap-graded asphalt concrete composed of a skeleton of crushed aggregates bound with a mastic mortar.It is a common practice to use additives or modified binders in the manufacture of these materials, especially to allow the binder content to be raised and to reduce segregation between the coarse aggregate and the mortar. Usually, fibers as well as polymers are used as additives or modified binders to SMA-mixes. To provide space for the fiber particles, it is necessary to create a 'gap' in the gradation curve of the aggregates, primarily in the $1 / 8$ to $1 / 4$ in. size range $[2,3]$. The fiber particles replace a portion of the rock particles that normally occupy this size range. The benefits of adding fibers to the mix are to increase pavement flexibility as well as fatigue life and to reduce crack reflection.

In a short time, stone mastic asphalt has managed to secure a good position in the asphalt world. It owns this popularity due to the high resistance to deformation and the high durability, which makes it an attractive alternative for closed asphalt in many applications. Recent experiences in Germany have shown that SMA also seems to have advantages over closed asphalt because of its sound properties (SMA has a sound level which lie $2.5 \mathrm{~dB}(\mathrm{~A})$ below the sound level of closed asphalt) [2].

Comparison between the three gradations: Specifications for SMA, coarse and dense gradations are shown in Tab. 1. Fig. 1 illustrates the aggregate gradations for SMA, coarse and dense gradations (average values) [4,5]. From the comparison between SMA and $\mathrm{CG}$, the following points can be underlined: 
1.Fines content: SMA contain approximately $6 \%$ higher than CG-mixes.

2.Quantity of sand: There are very small difference.

3.Binder: The binder used for SMA is a pure or modified bitumen. For pure bitumen, $\mathrm{AC} \quad 60-70$ or $\mathrm{AC} 80-100$ are the grades used (German specifications), corresponding to a pure bitumen for CG- and DG-mixes. The binder contents range from 6.5 to $8 \%$ for $\mathrm{SMA}$, from 3 to $6 \%$ for $\mathrm{CG}$-mixes and from 3.5 to $7 \%$ for DG-mixes (ASTM-specifications).

4.Laying Thickness: The thickness of SMA layer (0/11) ranges from 2.5 to 5 $\mathrm{cm}$ or 60 to $125 \mathrm{~kg} / \mathrm{m}^{2}[1,4]$, while there are no specifications for the required thickness of layers constructed using $\mathrm{CG}$-mixes.

5.Mechanical Performance: Mechanical performance required for SMA to determination of a void content in a laboratory. This value must be ranged between 2 to $4 \%$ in the Marshall test. Mixing temperature is around $135 \mathrm{C}$ for the test. Finally, field performance of SMA are void content $<6 \%$ and level of compaction is $97 \%$ higher than in the Marshall test. For CG- and DG-mixes, void content for Marshall specimens must be included between 3 to $5 \%$ and mixing temperature varied between 130 150 C.

Tab.1: Aggregate Gradations

\begin{tabular}{|l|l|l|l|}
\hline \multicolumn{1}{|c|}{ Sieve Size } & \multicolumn{3}{|c|}{ \% Passing by weight } \\
\hline & SMA & CG & \multicolumn{1}{c|}{ DG } \\
\hline $19.0 \mathrm{~mm}(3 / 4 \mathrm{in.})$ & 100 & 100 & $80-100$ \\
$12.5 \mathrm{~mm}(1 / 2 \mathrm{in.})$ & $90-100$ & $75-100$ & $-30-80$ \\
$9.5 \mathrm{~mm}(3 / 8 \mathrm{in.})$ & $60-85$ & $60-75$ & $60-80$ \\
$4.76 \mathrm{~mm}(3 / 16$ in.) & $30-50$ & $35-55$ & $48-65$ \\
$2.36 \mathrm{~mm}$ (No.4) & $20-32$ & $20-35$ & $35-50$ \\
$0.50 \mathrm{~mm}$ (No.100) & $11-24$ & $10-22$ & $13-30$ \\
$0.075 \mathrm{~mm}(\mathrm{No} .200)$ & $8-13$ & $2-8$ & $3-8$ \\
\hline
\end{tabular}

\section{MATERIALS}

\section{Asphalt}

One type of Asphalt cement was used in this study, Asphalt cement 60/70 pen . The properties of asphalt are given in Tab. 2 . 


\section{Aggregates}

The aggregate gradations lie within the GERMAN specifications for SMA [4] and the ASTM specifications for coarse and dense graded asphalt concrete mixtures (gradations $3 \mathrm{~B}$ and $4 \mathrm{C}$ ). Descriptions of aggregates are as follows:

\subsection{Coarse Aggregate (CA):}

Crushed stone aggregate with angular particles and rough surface texture (delivery from El-Suez region) was used in this investigation. The percentage of coarse aggregate in the mixes varied from 60 to $75 \%$

,by wet.

\subsection{Fine Aggregate (FA):}

Natural sand with particle size ranging from 0.09 to $2 \mathrm{~mm}$ was used as a fine aggregate in this study.

\subsection{Mineral Filler (MF):}

Lime stone dust was used as a mineral filler.

\section{Additives:}

Short textile fibers from polyacrylonitrile type. The fibers length ranged from 1 to $5 \mathrm{~mm}$. These fibers were used as additives to improve the mechanical performance of the asphalt mixtures. The percentages of textile fibers are 0.35 , 0.7 and $1.0 \%$ by wet. of dry aggregate.

Tab.2: Properties of Asphalt Cement

\begin{tabular}{|lr|l|}
\hline \multicolumn{1}{|c|}{ Property } & AC 60/70 \\
\hline Softening point (R.a.B) & $\left({ }^{\circ} \mathrm{C}\right)$ & 50 \\
Penetration at $25^{\circ} \mathrm{C}$ & $(1 / 10 \mathrm{~mm})$ & 62 \\
Ductility at $25^{\circ} \mathrm{C}$ & $(\mathrm{cm})$ & 117 \\
Specific Gravity & $(\mathrm{g} / \mathrm{cm} 3)$ & 1.03 \\
Flash Point & $\left({ }^{\circ} \mathrm{C}\right)$ & 230 \\
\hline
\end{tabular}




\section{TESTING PROGRAM}

A complete laboratory testing program was conducted on the different three aggregate gradations with-and without textile fibers. Two techniques were used for the assessment of asphalt concrete mixtures:

1.Marshall Test;

2.Indirect tensile strength test.

Tensile strength is a measure of the maximum tensile stress an asphalt paving mixes can withstand. This parameter is related to thermal and shrinkage cracking resistance. The indirect tensile strength was determined at a test temperature of $+5 \mathrm{C}^{\circ}$.

As mentioned before, three aggregate gradations were studied with different contents of asphalt, 5.5, 6.0,6.5 and $7.0 \%$ by weight To study the effect of fibers content on the mechanical properties of asphalt mixtures, three fiber contents were added $(0.35,0.7$ and $1.0 \%$ by weight $)$.

\section{TEST RESULTS AND DISCUSSION}

The following paragraphs discuss the results of laboratory tests and their analysis on three types of asphalt mixes (SMA-, CG- and DG-mixes).

\section{Mixtures without Fibers}

Effect of asphalt content as a function of aggregate gradation on the different properties of the three mixtures without additives (fibers) is discussed in the following paragraphs:

\section{-Marshall Stability vs. Asphalt Content as A function of Aggregate Gradation:}

Fig. 2 presents the effect of asphalt content on Marshall stability. It should be emphasized that the optimum asphalt content depends on the aggregate gradations. The optimum asphalt content for both SMA and CG-mixes lies at $6.5 \%$, while $6.0 \%$ asphalt content was the optimum value for DG-mixes. The highest Marshall stability was achieved using DG-mixes, while CG-mixes gave the lowest stability at all asphalt contents. 
-Voids Ratio vs. Asphalt Content as A function of Aggregate Gradation:

Effect of asphalt content on voids ratio for the three aggregate gradations is shown in Fig. 3 . As expected, the DG-mixes gave the lowest voids ratio, while the highest voids ratio was obtained using $\mathrm{CG}$-mixes.

\section{-Indirect Tensile Strength vs. Asphalt Content as A function of Aggregate Gradation:}

Fig. 4 shows the relationship between asphalt content and indirect tensile strength for the three mixes. The highest strength was obtained using DG-mixes, while the lowest strength was achieved by using CG-mixes.

The highest tensile strength was achieved for both CG- and SMA- mixes at $6.0 \%$ asphalt content, while $5.5 \%$ asphalt content gave the highest tensile strength for DG-mixes. It should be noted that the optimum asphalt content for Marshall stability is $0.5 \%$ higher than the optimum asphalt content for indirect tensile strength.

\section{-Strain vs. Asphalt Content as A function of Aggregate Gradation:}

Effect of asphalt content on the strain as a function of aggregate gradation is shown in Fig. 5. The highest strain was obtained using CG-, DG- and SMAmixes, respectively. The relation between flow values and asphalt content is the same relation between strain and asphalt content.

\section{Mixtures With Fibers:}

Textile fibers was added to the different three mixes at $6.5 \%$ asphalt content in three concentrations $0.35,0.7$ and $1.0 \%$ by weight. Effect of textile fibers content on the different properties was as follows:

\section{-Effect of Fibers Content on Marshall Stability:}

The relationship between Marshall stability and fibers content for all three mixtures is shown in Fig.6. By adding fibers, Marshall stability increased for all three gradations and at the three fibers contents .

For CG-mixes, Marshall stability increased from $5.5 \mathrm{kN}$ for conventional asphalt mix without fibers to $7.8 \mathrm{kN}$ for the mixture with $1.0 \%$ fiber content. For SMA-mixes, it increased to its highest value $(7.65 \mathrm{kN})$ at $0.7 \%$ fibers content. For DG-mixes, there was no significant difference between the stability for mixes without- and with fibers (max. improvement in Marshall stability was 
about $8 \%$ and achieved by adding $0.35 \%$ fibers content). This may be return to dense gradation mixes has low voids content, and subsequently it needs low fibers concentration ( optimum fibers content $=0.35 \%$ ).

\section{-Effect of Fibers Content on Indirect Tensile Strength:}

Fig. 7 presents the relation between fibers content and the indirect tensile strength as a function of aggregate gradation. A large difference in strength between the three gradations was obtained when adding $0.35 \%$ fibers. This difference in tensile strength was reduced gradually by increasing fibers content. By adding 1.0\% Fibers, there was no difference between both CG- and DGmixes. The curve of DG-mixes was increased to an optimum value at $0.7 \%$ fibers content and then decreased. This may be due to the small voids content of DG-mixes. The indirect tensile strength curves of both SMA- and CG-mixes were parallel, but the curve of SMA-mixes was higher than that of the CGmixes.

\section{-Effect of Fibers Content on Strain:}

Fig. 8 shows the relation between the strain and fibers content. It should be noticed that the values of the strain for CG-mixes were higher those the strain of SMA- as well as DG-mixes. This result was achieved for all mixes withoutand with fibers. There was no significant difference in the strain for both SMAand DG-mixtures.

By adding fibers, the strain was increased for the three mixtures. This means that the flexibility of the pavement was improved by adding textile fibers to the asphalt mixtures and subsequently the surface- and fatigue cracking may be reduced or prevented.This finding is important with respect to resistance of pavements subjected to low temperatures. This may be attributed to the low voids content of dense gradation mixes.

\section{CONCLUSIONS}

Different mixes made from various combinations of three aggregate gradations,stone-mastic-asphalt (SMA), coarse gradation (CG) and dense gradation (DG) without- and with fibers, were tested using Marshall- and indirect tensile strength test methods. 
The following conclusions can be summarized from this research: 1-Generally, coarse gradation, 3B lies within the ranges of SMA gradations. Only, the filler content for CG-mixes is lower than that of SMA ( $2-8 \%$ for CGand $8-13 \%$ for SMA mixes).

2-For asphalt mixes without textile fibers, the lowest Marshall stability was achieved for CG-mixes, on the other hand, the asphalt mixes with fibers Marshall stability results were as follows:

a) For CG-mixes, the stability was increased rapidly and reached maximum value at $1.0 \%$ fibers content.

b) For SMA-mixes, stability increased markedly to an optimum value at $0.7 \%$ fibers content and then decreased.

c) For DG-mixes, the highest stability was achieved when adding $0.35 \%$ fibers.

3-Effect of fibers on the indirect tensile strength was typical such as its effect on Marshall stability. Moreover, the highest tensile strength was obtained at $0.5 \%$ asphalt content lower than the optimum for Marshall stability.

\section{REFERENCES}

[1] J.P.Michant : Ruflex or Stone Mastic Asphalt. European Asphalt Magazine, 1/1995, pp.25-29.

[2] D.GroBhans : Asphaltbefestigungen mit hoher Standfestigkeit. Bitumen 1/1990, pp.13-18.

[3] W.Arand, O.Harders and B.Herr: Asphalt Containing Conventional and Polymer-modified Bitumen in high and low Temperature Conditions. European Asphalt Magazine, 3/1992, pp.47-60.

[4] Zusatzlische Technische Vertragsbedingungen and Richtlinien fur den Bau von Fahrbahndecken aus Asphalt, ZTV bit-StB 84.

[5] General Authority of Egyptian Highways and Bridges: Standard Specifications of Highway Constructions, Part 2, Cairo, 1976. 


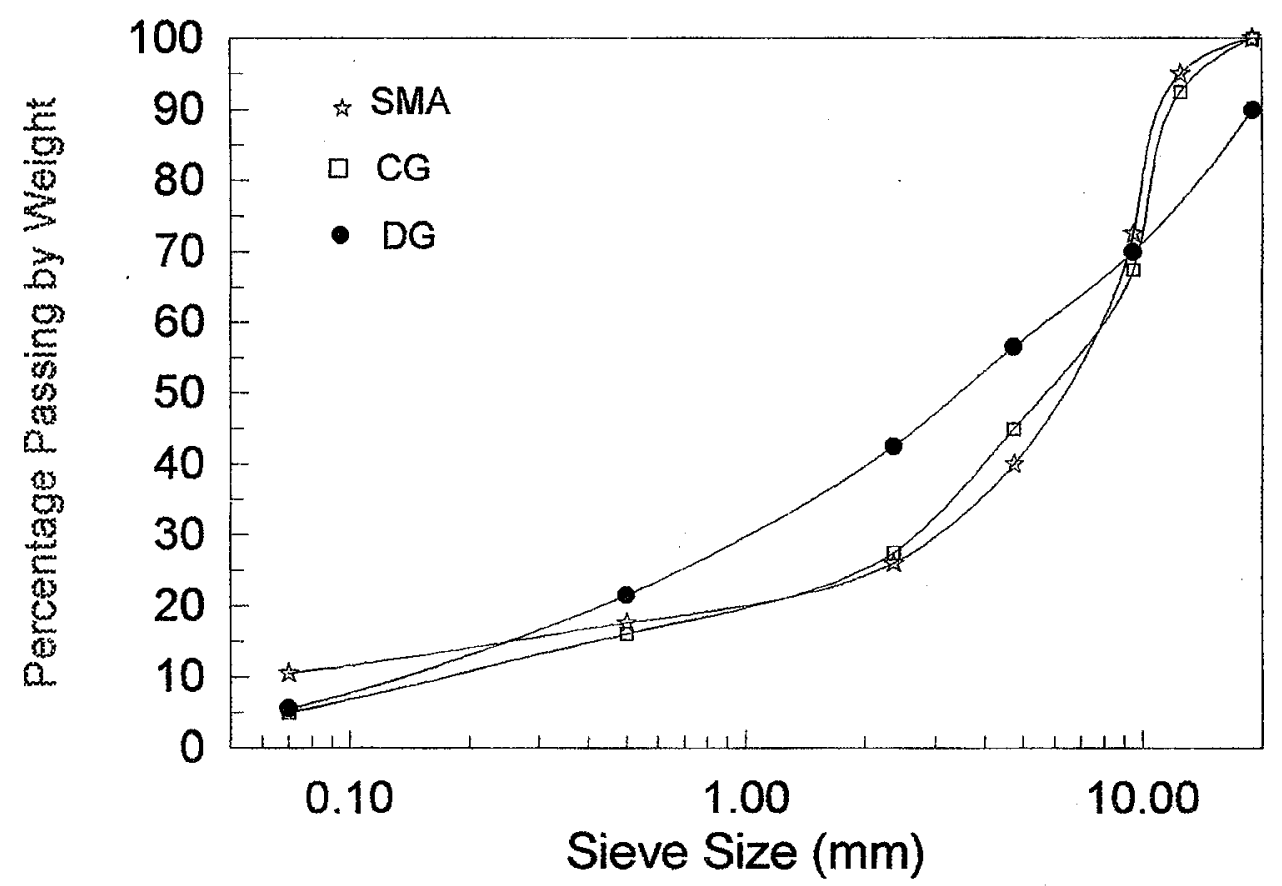

Fig.1: Selected aggregate gradations for SMA-, CG-and DG-mixes.

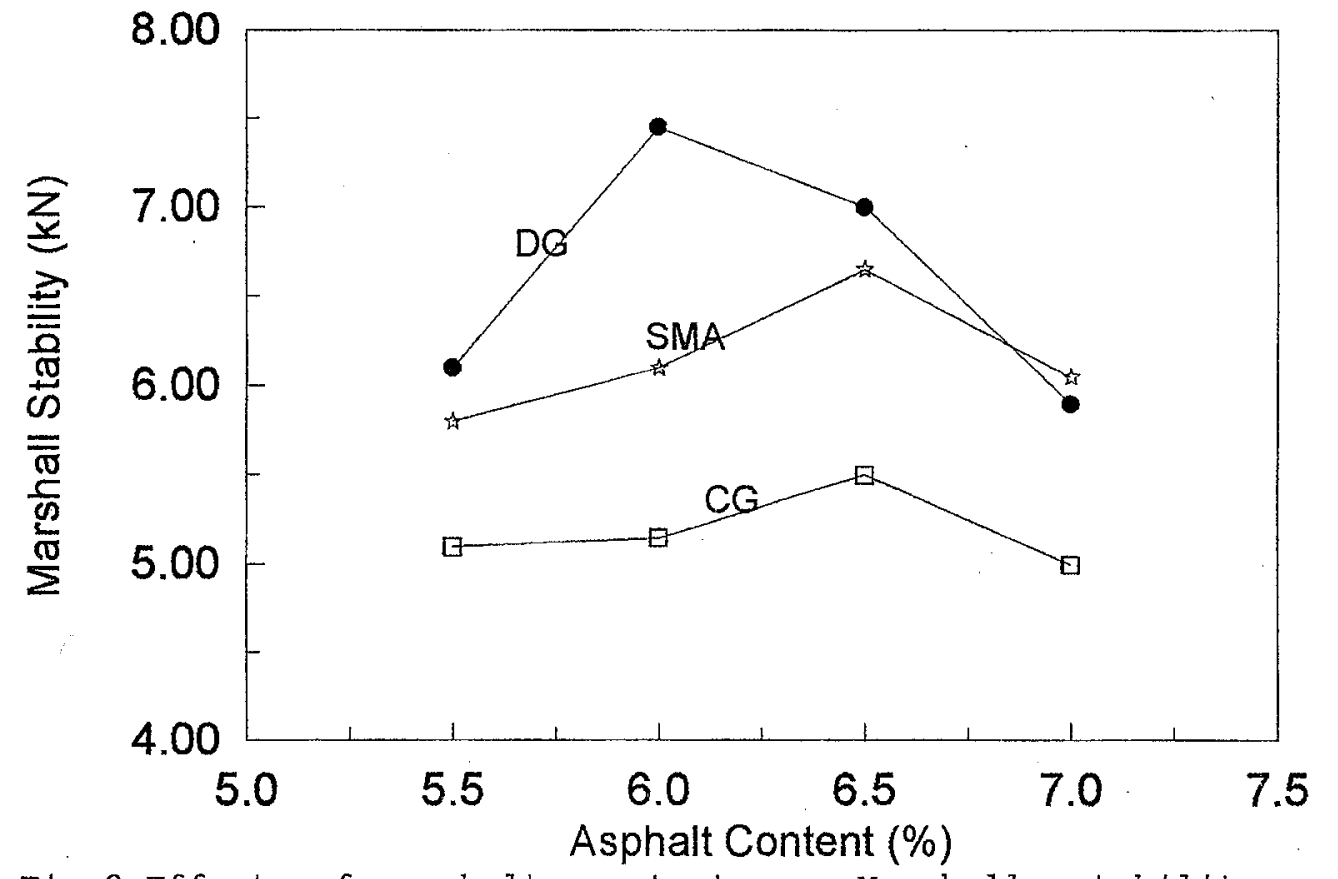

Fig.2:Effect of asphalt content on Marshall stability as a function of aggregate gradations. 


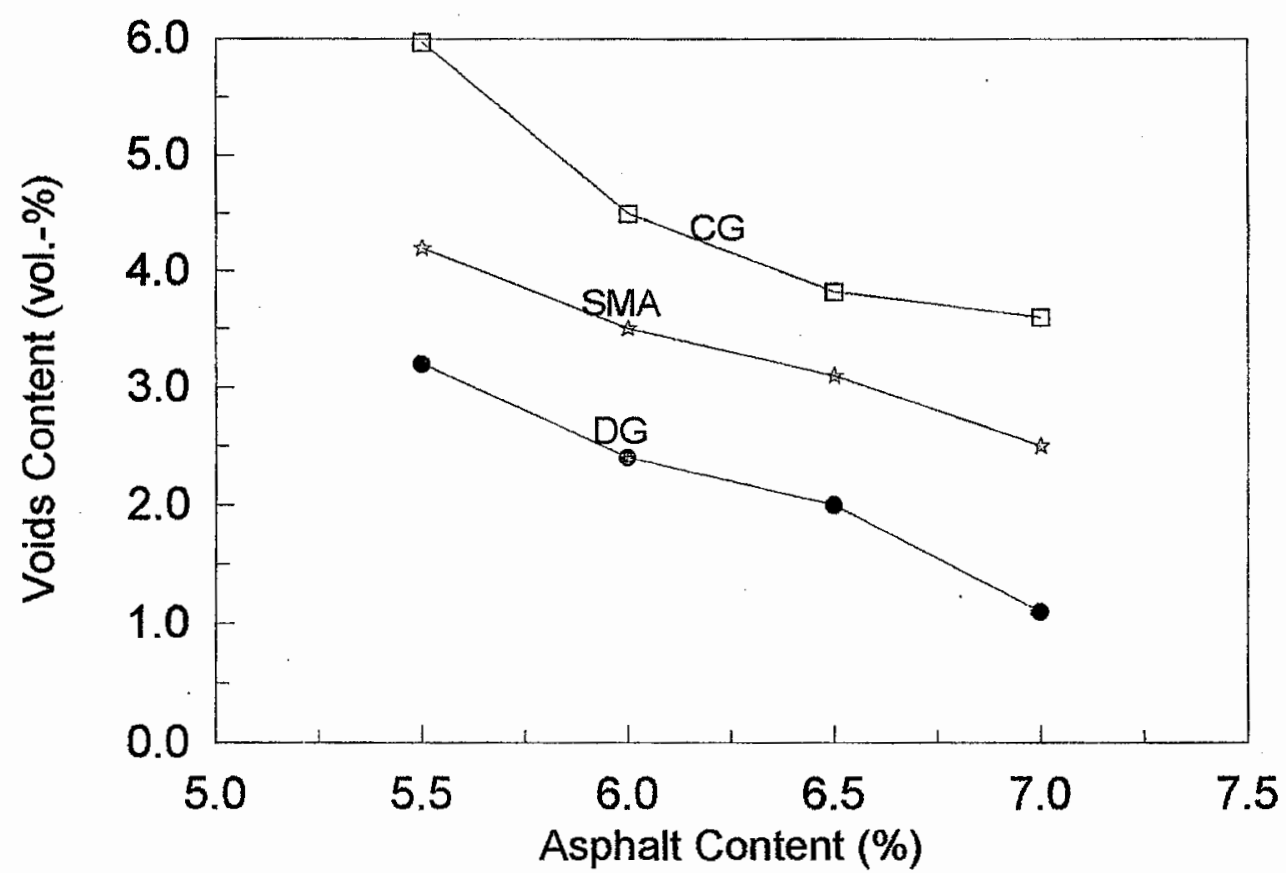

Fig.3:Effect of asphalt content on voids ratio as a function of aggregate gradation.

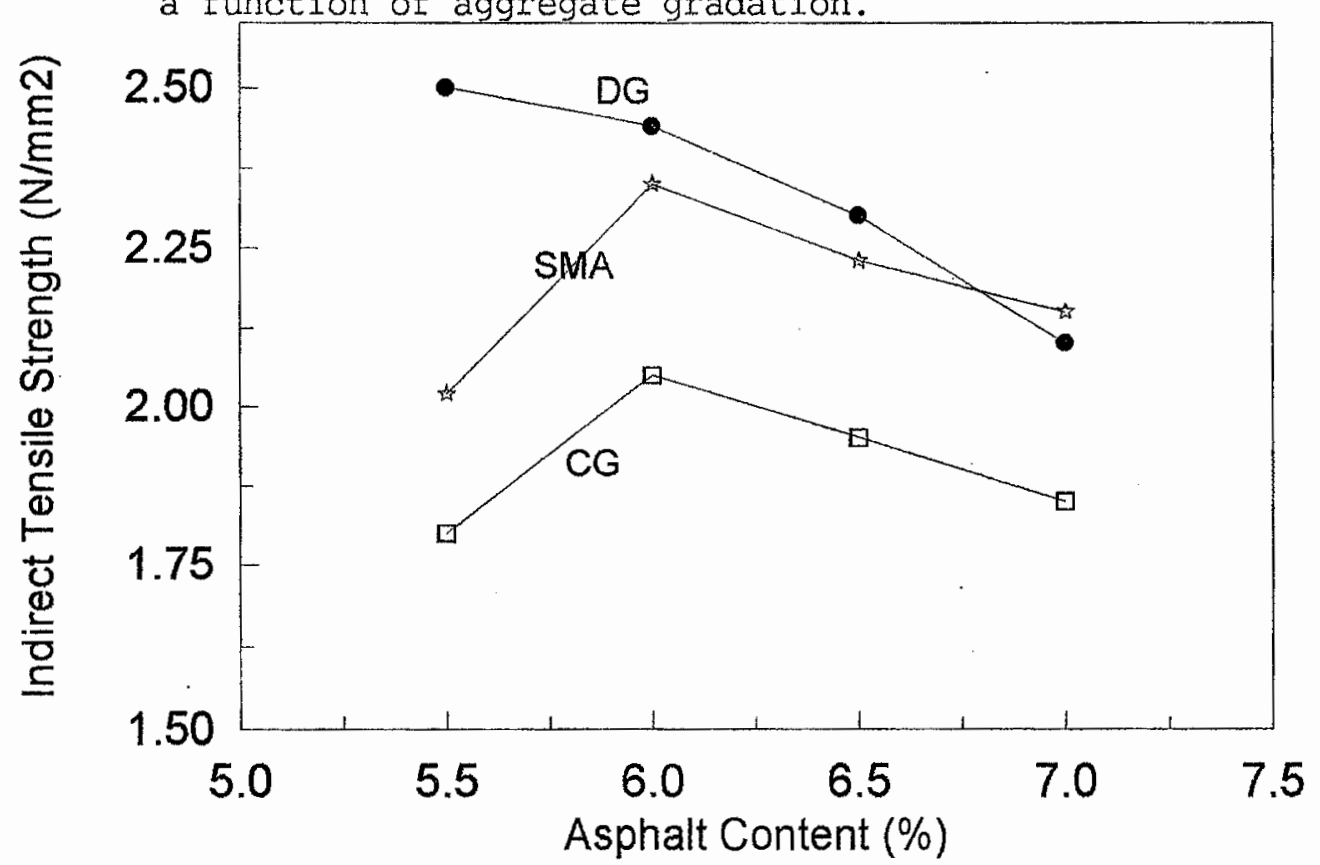

Fig.4:Effect of asphalt content on the indirect tensile strength as a function of aggregate gradation: 


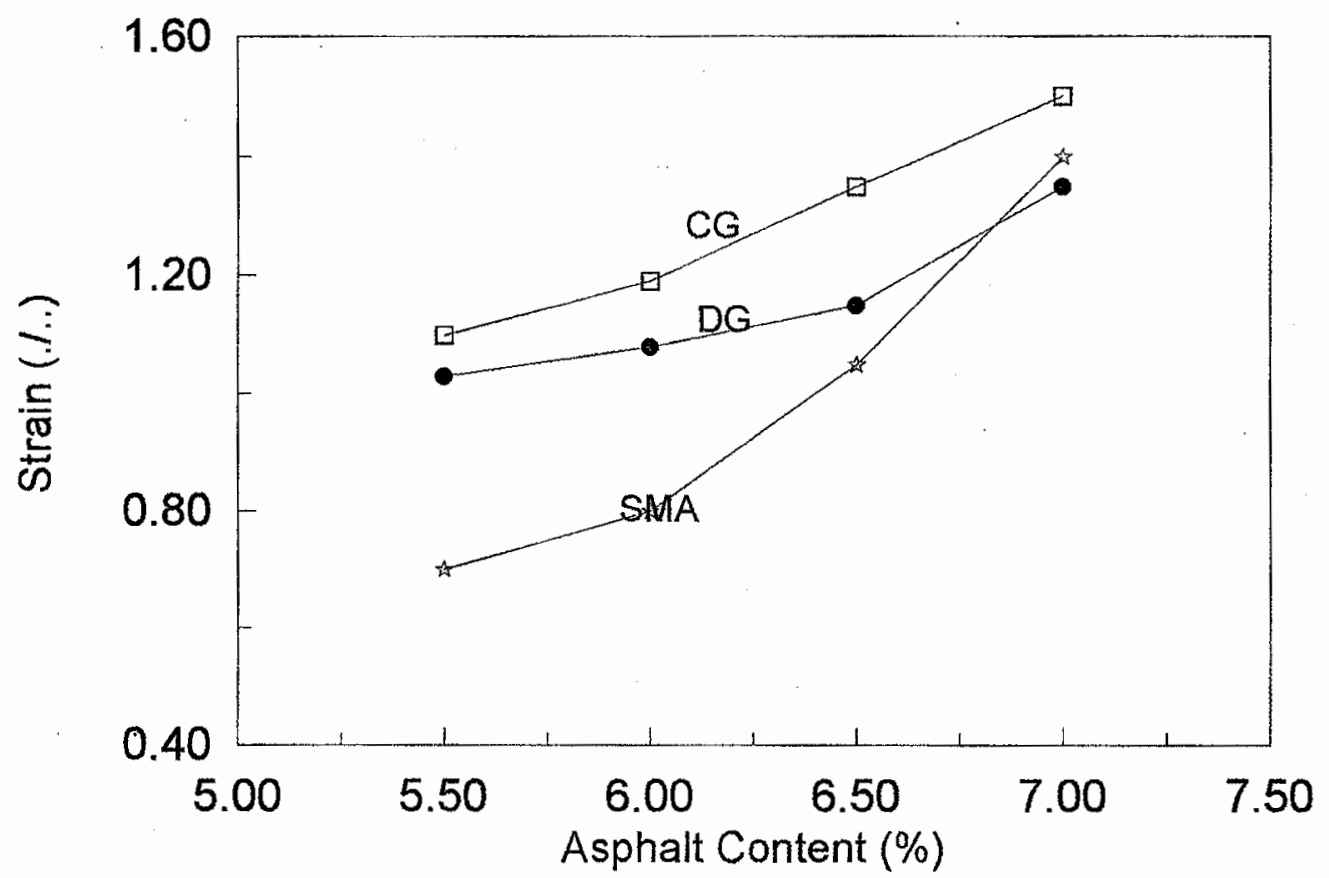

Fig.5: Effect of asphalt content on the strain as a function of aggregate gradation.

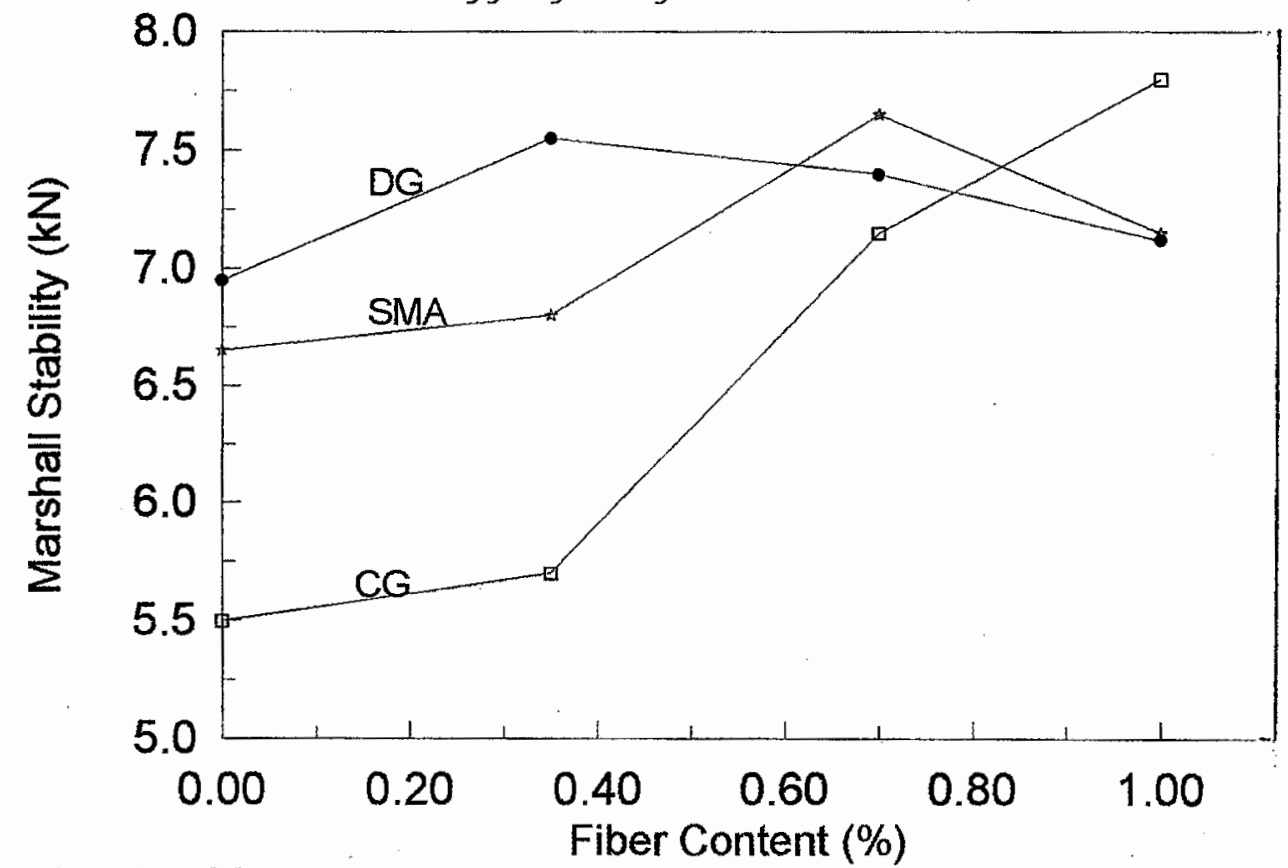

Fig.6:Effect of fibers content on Marshall stability as a function of aggregate gradation. 


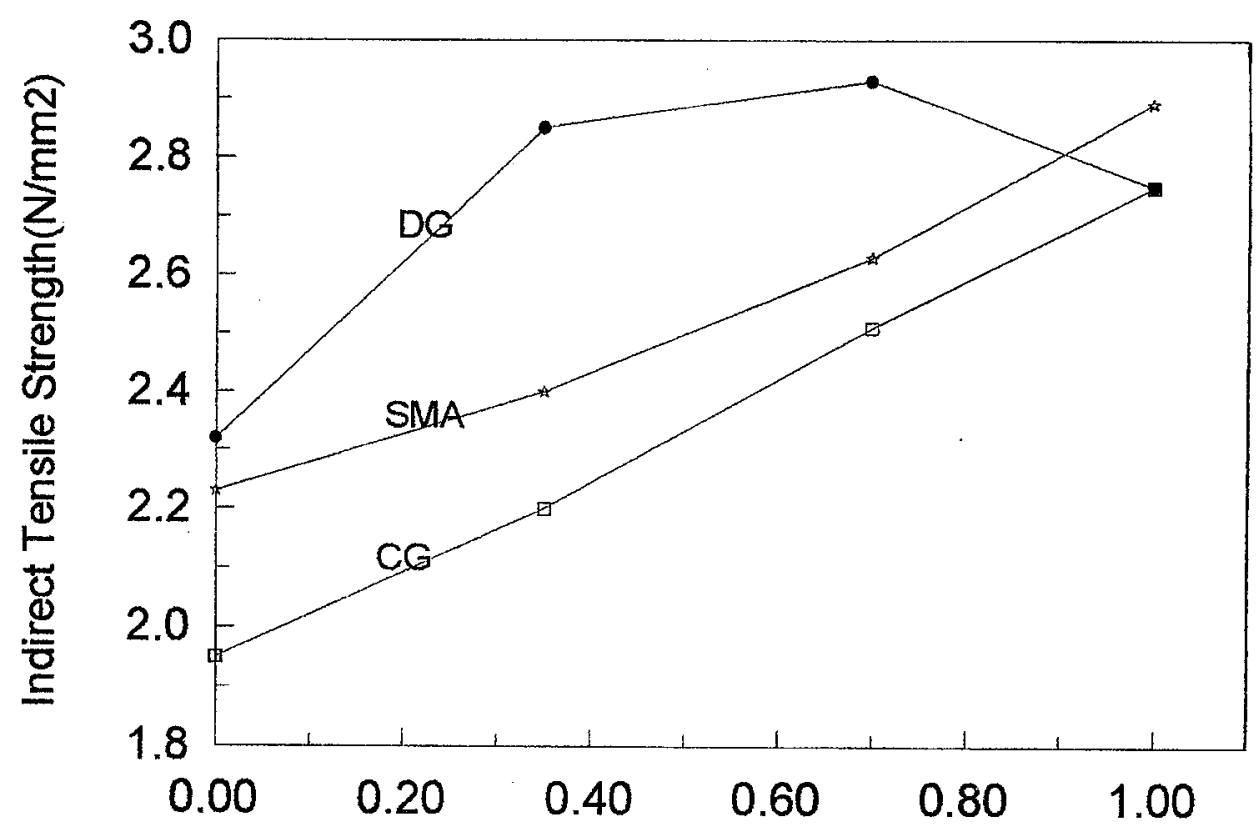

Fiber Content (\%)

Fig.7:Effect of fibers content on the indirect tensile strength as a function of aggregate gradations.

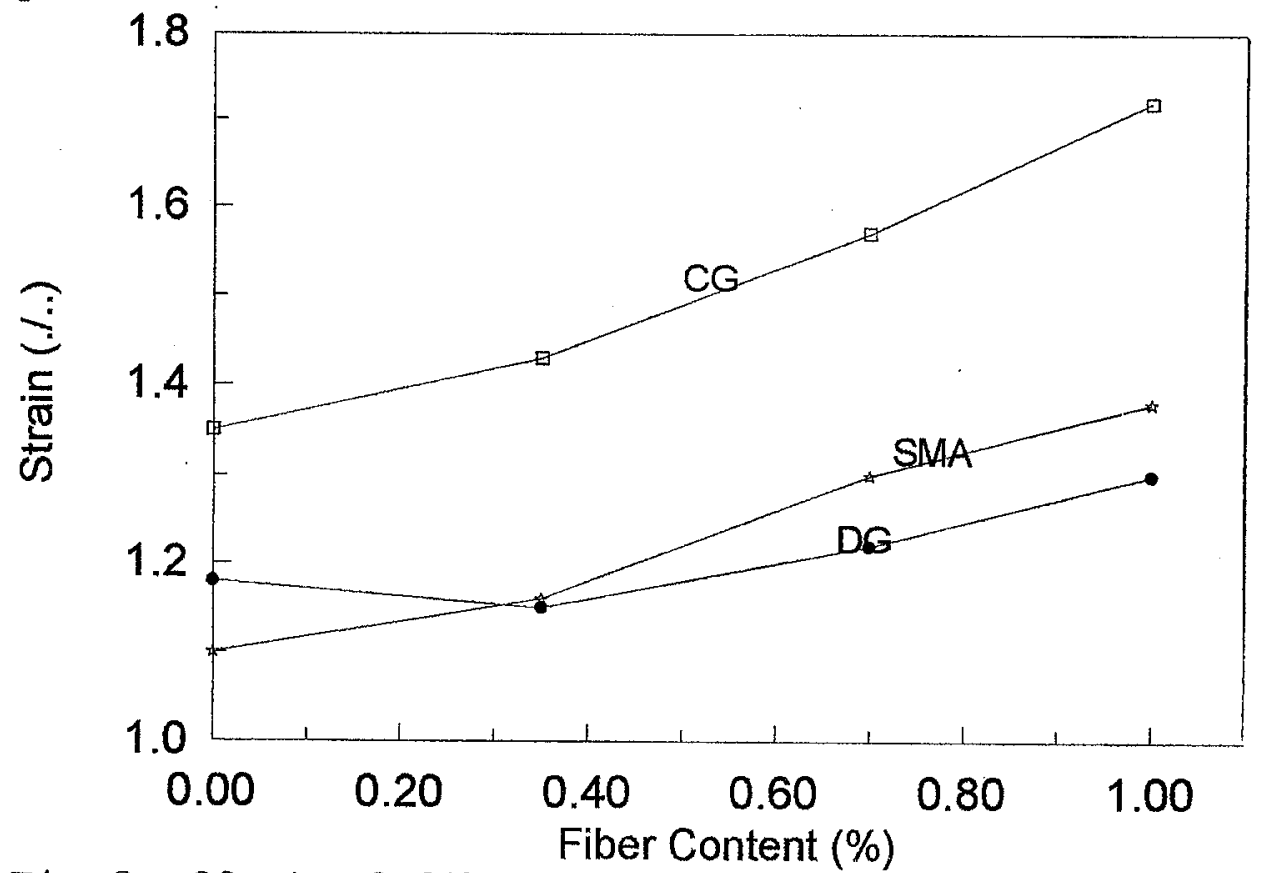

Fig.8:Effect of fibers content on strain values as a function of aggregate gradation. 


\section{ألسياف النسـيجي كتسسليح خلطات الخر سانة الاسفلتية}

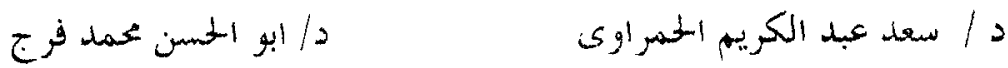

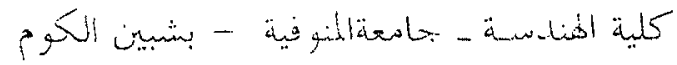

$\therefore$ الملتخصر

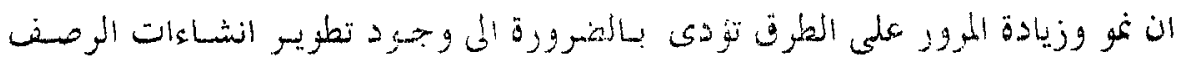

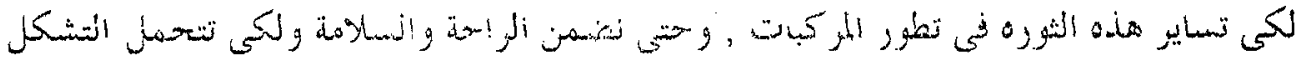

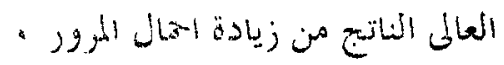

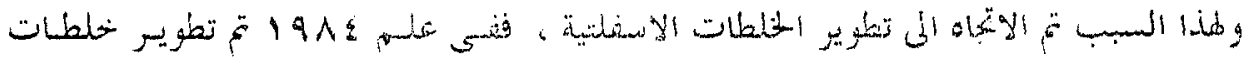

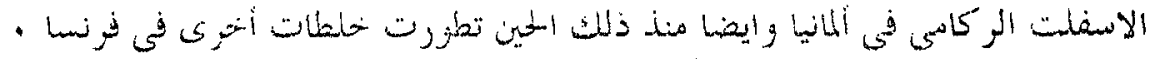

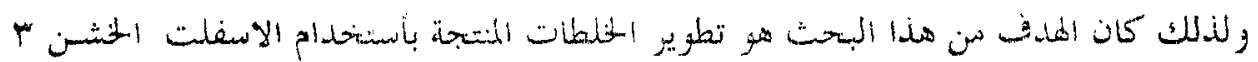

ب وذلكك بأضافة ألياف النسيج لملأ الفراغات ستى تكـون في حسلدود المو اصفات وأيضسا مقيارنسة

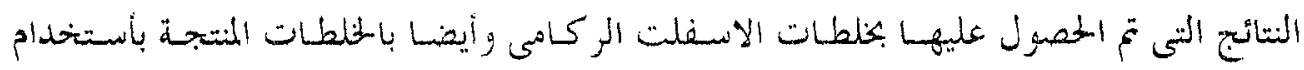

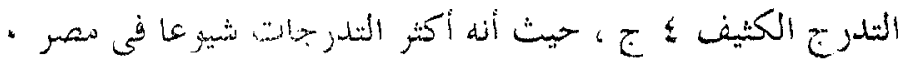

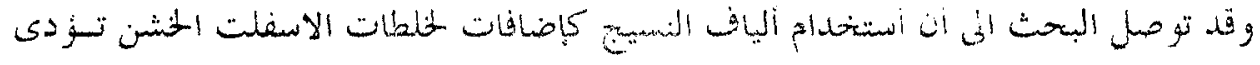

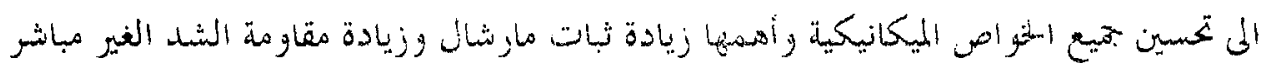

